\title{
SEOM clinical guidelines in advanced and recurrent breast cancer (2018)
}

\author{
J. I. Chacón López-Muñiz ${ }^{1,2}$ (D) L. de la Cruz Merino ${ }^{3} \cdot$ J. Gavilá Gregori ${ }^{4} \cdot$ E. Martínez Dueñas ${ }^{5} \cdot$ M. Oliveira ${ }^{6}$. \\ M. A. Seguí Palmer ${ }^{7} \cdot$ I. Álvarez López ${ }^{8} \cdot$ S. Antolin Novoa ${ }^{9} \cdot$ M. Bellet Ezquerra ${ }^{10} \cdot$ S. López-Tarruella Cobo ${ }^{11}$
}

Received: 3 December 2018 / Accepted: 5 December 2018 / Published online: 8 January 2019

(c) The Author(s) 2019

\begin{abstract}
Although the metastasic breast cancer is still an incurable disease, recent advances have increased significantly the time to progression and the overall survival. However, too much information has been produced in the last 2 years, so a well-based guideline is a valuable document in treatment decision making. The SEOM guidelines are intended to make evidence-based recommendations on how to manage patients with advanced and recurrent breast cancer to achieve the best patient outcomes based on a rational use of the currently available therapies. To assign a level of certainty and a grade of recommendation the United States Preventive Services Task Force guidelines methodology was selected as reference.
\end{abstract}

Keywords Advanced $\cdot$ Loco-regional recurrence $\cdot$ Breast cancer $\cdot$ SEOM $\cdot$ Guidelines

J. I. Chacón López-Muñiz

jignaciochacon@gmail.com

L. de la Cruz Merino

lucme12@yahoo.es

J. Gavilá Gregori

jgavila@fivo.org

E. Martínez Dueñas

eduardo.martinez@hospitalprovincial.es

M. Oliveira

moliveira@vhio.net

M. A. Seguí Palmer

masegui@gmail.com

I. Álvarez López

ISABELMANUELA.ALVAREZ@osakidetza.eus

S. Antolin Novoa

silvia.antolin.novoa@sergas.es

M. Bellet Ezquerra

mbellet@vhio.net

S. López-Tarruella Cobo

slopeztarruella@gmail.com

1 Servicio de Oncología Médica, Hospital Virgen de la Salud, Avda. de Barber, 30, 45004 Toledo, Spain
2 GEICAM, Madrid, Spain

3 Servicio de Oncología Médica, Medicine Department, Hospital Virgen Macarena, University of Sevilla, Seville, Spain

4 Servicio de Oncología Médica, Fundación Instituto Valenciano de Oncología, Valencia, Spain

5 Servicio de Oncología Médica, Hospital Provincial de Castellón, Castellón, Spain

6 Vall d'Hebron University Hospital and Vall d'Hebron Institute of Oncology, Barcelona, Spain

7 Servicio de Oncología Médica, Corporació Sanitaria Parc Tauli, Sabadell, Barcelona, Spain

8 Servicio de Oncología Médica, Hospital Universitario Donostia/Donostiako Unibertsitate Ospitalea, Donostia, Spain

9 Servicio de Oncología Médica, Hospital Universitario A Coruña, A Coruña, Spain

10 Vall d'Hebron University Hospital and Vall d'Hebron Institute of Oncology (VHIO), Barcelona, Spain

11 Servicio de Oncología Médica, Hospital General Universitario Gregorio Marañón, Instituto de Investigación Sanitaria Gregorio Marañón (IiSGM), Universidad Complutense, CiberOnc, GEICAM, Madrid, Spain 


\section{Introduction}

Breast cancer (BC) represents the first cause of invasive cancer in the Spanish women, accounting for $29 \%$ of all female cancers. According to recent data, 26,730 new cases and 6477 deaths are estimated annually in Spain [1].

Metastatic BC (MBC) remains virtually an incurable disease, with reported median overall survival (OS) of approximately 2 years. However, improved OS (up to 5 years) has been observed recently for certain subtypes, particularly in HER2-positive disease. De novo metastatic disease has better 5-year OS that recurrent MBC and prognosis appear to improve over time [2].

Patients with loco-regional recurrence (LRBC) may or may not be amenable to radical local treatment. Overall, according to a Spanish study, an increase in OS has been observed in the recent years in LRBC patients [3].

\section{Methodology}

The SEOM guidelines have been developed with the consensus of ten breast cancer oncologists from the cooperative groups GEICAM (Spanish Breast Cancer Research Group) and SOLTI (Spanish Collaborative Group for the Study, treatment and other experimental strategies in solid tumors). To assign a level of certainty (LC) and a grade of recommendation (GR) to the different statements described in the clinical guidelines, the United States Preventive Services Task Force (USPSTF) guidelines methodology was selected as reference, as the previously adopted for the former version of SEOM recommendations [4] (Table 1).

\section{General overview of advanced breast cancer}

\section{Goals of treatment}

The two main goals for the treatment of MBC patients are to improve survival and to optimize the quality of life [5]. For LRBC patients for whom a radical approach is not feasible, the aims of the treatment are similar to that in $\mathrm{MBC}$ patients. Conversely, for those LRBC amenable to a local treatment the objectives will be to eradicate all macroscopic diseases and to improve both disease-free survival and overall survival.

- Since the diagnosis of advanced or recurrent BC is made, patients should also be offered appropriate multidisci-

Table 1 Strength of recommendation and level of certainty according to the United States Preventive Services Task Force (USPSTF) after July 2012 [4]

\begin{tabular}{|c|c|}
\hline Category & Definition \\
\hline \multicolumn{2}{|c|}{ Strength of recommendations (grade) } \\
\hline A & The USPSTF recommends the service. There is high certainty that the net benefit is substantial \\
\hline B & $\begin{array}{l}\text { The USPSTF recommends the service. There is high certainty that the net benefit is moderate or there is moderate certainty that } \\
\text { the net benefit is moderate to substantial }\end{array}$ \\
\hline $\mathrm{C}$ & $\begin{array}{l}\text { The USPSTF recommends selectively offering or providing this service to individual patients based on professional judgment and } \\
\text { patient preferences. There is at least moderate certainty that the net benefit is small }\end{array}$ \\
\hline $\mathrm{D}$ & $\begin{array}{l}\text { The USPSTF recommends against the service. There is moderate or high certainty that the service has no net benefit or that the } \\
\text { harms outweigh the benefits }\end{array}$ \\
\hline I & $\begin{array}{l}\text { The USPSTF concludes that the current evidence is insufficient to assess the balance of benefits and harms of the service. Evi- } \\
\text { dence is lacking, of poor quality, or conflicting, and the balance of benefits and harms cannot be determined }\end{array}$ \\
\hline \multicolumn{2}{|c|}{ Levels of certainty regarding net benefit } \\
\hline High & $\begin{array}{l}\text { The available evidence usually includes consistent results from well-designed, well-conducted studies in representative primary } \\
\text { care populations. These studies assess the effects of the preventive service on health outcomes. This conclusion is therefore } \\
\text { unlikely to be strongly affected by the results of future studies }\end{array}$ \\
\hline Moderate & $\begin{array}{l}\text { The available evidence is sufficient to determine the effects of the preventive service on health outcomes, but confidence in the } \\
\text { estimate is constrained by such factors as the number, size, or quality of individual studies; inconsistency of findings across } \\
\text { individual studies; limited generalizability of findings to routine primary care practice; lack of coherence in the chain of evi- } \\
\text { dence. As more information becomes available, the magnitude or direction of the observed effect could change, and this change } \\
\text { may be large enough to alter the conclusion }\end{array}$ \\
\hline Low & $\begin{array}{l}\text { The available evidence is insufficient to assess effects on health outcomes. Evidence is insufficient because of: the limited number } \\
\text { or size of studies; important flaws in study design or methods.; inconsistency of findings across individual studies; gaps in the } \\
\text { chain of evidence; findings not generalizable to routine primary care practice; lack of information on important health out- } \\
\text { comes. More information may allow estimation of effects on health outcomes }\end{array}$ \\
\hline
\end{tabular}


plinary care, as it may have an impact in OS, including symptom-related intervention ( $L C$ high; GR A).

- Research is a priority in this setting. Participation in well-designed, independent, prospective trials should be offered to all eligible patients, whenever possible ( $L C$ high; GR A).

For all indications and breast cancer types, palliative treatment is strongly recommended when indicated.

\section{Diagnosis of recurrence and metastatic disease}

- Clinical loco-regional recurrence should be confirmed by biopsy in all LRBC before planning any therapeutic strategy (LC high; GR A).

- Both in LRBC and in MBC (primary or relapsed) the histologic analyses should be performed if possible. In recurrences, it will serve to confirm neoplastic recurrence and to recheck histologic subtype, as changes in hormone receptors (HR) and HER2 between primary tumor and recurrences have been reported [6] (LC high; GR A).

\section{Staging}

- For both MBC and LRBC clinical evaluation should include medical history and physical examination. Minimal staging workup should include imaging techniques of chest, abdomen and bone, hematology and biochemistry. The recommended imaging techniques are body TC and bone scintigraphy (LC moderate; GR B).

- The role of tumor markers (TM) in the follow-up of early BC patient is controversial [7] (LC low; GR C). Once recurrence is diagnosed, basal TM (CEA, CA15.3 and/ or Ca 27.4) may be performed. Because, if elevated, may help to monitor disease response to therapy, especially in the presence of non-measurable disease ( $L C$ low; GR C). However, treatment decisions should not be based only on the variation of TM levels ( $L C$ moderate; $G R A$ ).

- Overall, the use of systematic brain image in all patients in the absence of suspicious symptoms is not recommended, even in HER2-positive disease (LC moderate; $G R B)$.

- The use of Positron emission tomography (PET) is controversial in MBC, but can be used instead of TC and bone scan, if available (level of evidence low, GR B) [8]. In the postoperative surveillance PET/TC is recommended only in cases of equivocal and conflicting findings [9] (LC low; GR C).

\section{Loco-regional recurrence management}

\section{Local therapy}

\section{Local only recurrence}

Patients with local and regional disease are divided into three groups.

- Initial treatment with lumpectomy + radiation therapy (RT): treat recurrence with total mastectomy + axillary lymph node staging if level II/III axillary dissection not previously done [10] (LC moderate; GR B). Limited data suggest that a repeated sentinel node biopsy may be successfully performed in patients who have previously undergone breast-conserving therapy and sentinel node biopsy [11] ( $L C$ low; GR C). For isolated ipsilateral breast cancer recurrences, breast conservative surgery plus partial breast irradiation is an alternative option [12] (LC moderate; GR B).

- Initial treatment with mastectomy and no prior RT: treat recurrence with surgical resection if possible $+\mathrm{RT}[13$, 14] (LC low; GR B).

- Initial treatment with mastectomy + level I/II axillary dissection and prior RT: surgical resection if possible [13] (LC low; GR B). Limited data regarding additional irradiation [15] (LC low; GR C).

\section{Regional only or local and regional recurrence}

- Axillary recurrence: surgical resection if possible $+\mathrm{RT}$ if possible [16] (LC moderate; GR B).

- Supraclavicular and internal mammary node recurrence: RT if possible [17] (LC moderate; GR B).

Patients with disease not amenable to radical local treatment should be treated with induction chemotherapy (CT), endocrine or anti-HER2 therapy when indicated, and then palliative radiation, which is mandatory if the patient is radiation naïve $[14,18]$ (LC low; GR B).

\section{Systemic therapy}

CT after first local or regional recurrence improves longterm outcomes primary in ER negative disease. Endocrine therapy in this setting improves long-term outcomes for ER positive disease [19] ( $L C$ moderate; GR B). In case of HER2-positive disease and the absence of previous antiHER2 adjuvant treatment, trastuzumab is indicated [20] ( $L C$ moderate; GR B). However, the optimal strategy in case 
of previous adjuvant anti-HER2 treatment is unknown. CT is indicated for endocrine-resistant disease, as first line in triple-negative disease and combined with anti-HER2 drugs in HER2-positive disease.

In patients with disease not amenable to radical local treatment, the choice of palliative systemic therapy should be made according to the principles defined for metastatic $\mathrm{BC}(L C h i g h ; G R A)$.

\section{Endocrine therapy in advanced HR-positive/ HER2-negative breast cancer}

Since the last SEOM guideline for MBC on 2015 several advances have occurred in the treatment of endocrine therapy (ET) of luminal MBC [21]. Endocrine therapy includes ER-targeting drugs as single agents or in combination with drugs targeting pathways involved in hormone resistance such as the mTOR inhibitor, everolimus (PIK3/AKT/mTOR pathway) and CDK4/6 inhibitors (cell cycle pathway). ERtargeting drugs can act by lowering the levels of circulating estrogens or those acting directly in the ER (Table 2).

\section{General considerations}

The preferred treatment for luminal $\mathrm{ABC}$ is ET in the majority of cases. Sequential ET should be used as long as the patient seems to be benefiting from ET and does not have evidence of immediately life-threatening disease or rapid progression of visceral disease with organ dysfunction (visceral crisis), or when there is an evidence of endocrine resistance. The presence of visceral involvement alone is not a contraindication for the use of ET ( $L C h i g h ; G R A)$.

The choice of which ET to use in each situation should take into consideration: (1) prior (neo) adjuvant ET vs "de novo" ABC; (2) Disease-free interval; (3) response to prior ET; (4) burden of disease and symptoms; (5) menopausal status; (6) comorbidities; (7) patient preferences and (8) costs and availability.

Since eventually all patients develop resistance or primarily resistant to ET, this must be considered before starting any therapy (first or next lines). Although a clear and consistent definition of resistance to ET is lacking, endocrine resistance has been defined by consensus (Table 3), as well as the type of ET that should be used in first and second lines (Table 4) [5, 22].

The optimal sequence of endocrine-based therapy is uncertain. Available options for pre- and perimenopausal women with ovarian function suppression (OFS)/ovarian
Table 2 Common classes of endocrine therapy

\begin{tabular}{lll}
\hline Mechanism of action & Class & Agent \\
\hline Estrogen receptor blockage & SERM & Tamoxifen, toremifen \\
& SERD & Fulvestrant \\
Estrogen deprivation & Ovarian ablation & Surgery, radiation \\
& Ovarian suppression with GnRH & Goserelin \\
& analogs & Triptorelin \\
& NSAI & Leuprolide \\
& & Anastrozole \\
Unknown & SAI & Letrozole \\
& Progestins & Exemestane \\
& & Megestrol acetate \\
\hline
\end{tabular}

Mechanism of action

SERM selective estrogen receptor modulator, SERD selective estrogen receptor downregulator (Fulvestrant $500 \mathrm{mg} / \mathrm{month}$ with loading dose is the recommended dosage), GnRH gonadotropin-hormone releasinghormone, NSAI non-steroideal aromatase inhibitors (3rd generation), SAI steroidal aromatase inhibitors (3rd generation)

Table 3 Definition of endocrine resistance levels [5, 22]

\begin{tabular}{ll}
\hline Primary endocrine resistance & $\begin{array}{r}\text { Relapse while on the first } 2 \text { years of adjuvant endocrine therapy (ET), or progressive disease (PD) within first } \\
6 \text { months of first-line ET for ABC, while on ET }\end{array}$ \\
Secondary endocrine resistance & $\begin{array}{r}\text { Relapse while on adjuvant ET but after the first } 2 \text { years, or relapse within } 12 \text { months of completing adjuvant } \\
\text { ET, or PD } \geq 6 \text { months after initiating ET for ABC, while on ET }\end{array}$
\end{tabular}


Table 4 Consensus definition of 1 st and 2nd lines of endocrine therapy (ET) [5, 22]

1st line ET: (endocrine sensitive patients)

2nd line ET
Newly diagnosed (de novo) ABC

Relapse $>12$ months from completion of (neo) adjuvant endocrine therapy with no treatment for advanced or metastatic disease (treatment naïve in the advanced setting)

Relapse on or within 12 months from completion of (neo) adjuvant endocrine therapy with no treatment for advanced or metastatic disease (early relapse)

Progression after 1st line of endocrine therapy for advanced disease (as described before)

Table 5 Definitions and menopausal status [24]

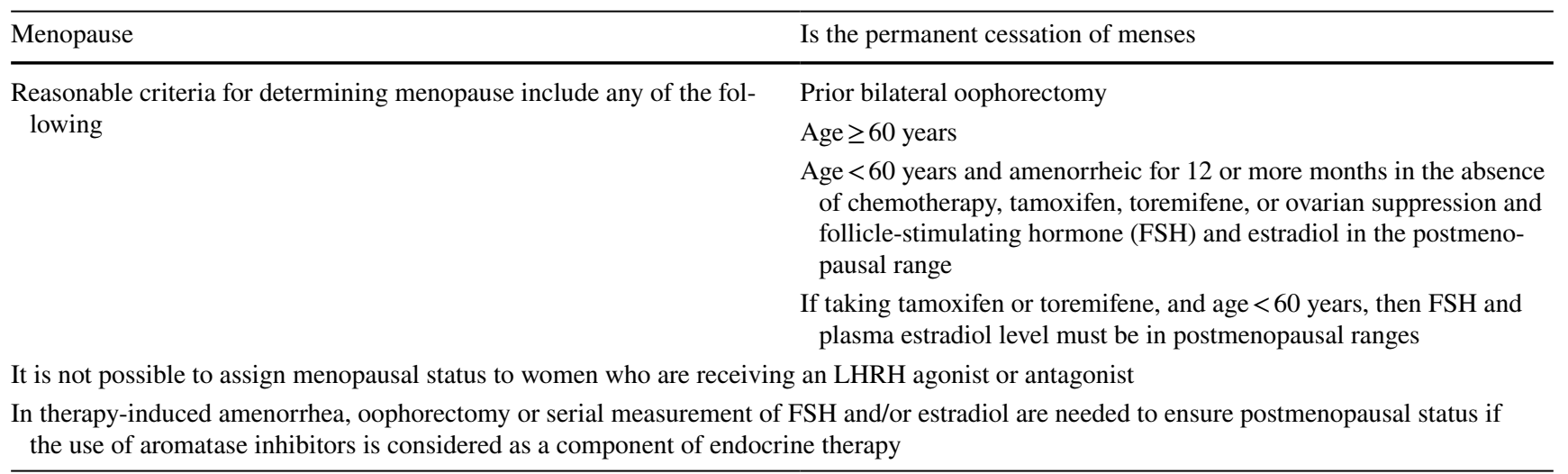

function ablation (OFA), and post-menopausal women include aromatase inhibitor (AI), tamoxifen, fulvestrant, $\mathrm{AI} /$ fulvestrant plus CDK 4/6 inhibitor, and ET plus everolimus. In later lines, also megestrol acetate and oestradiol, as well as repetition of previously used agents, may be used.

Besides the ER/PR positivity, as defined by international guidelines [23], we do not have another useful biomarker to select ET.

As the blockage of the estrogen signal is the mainstay of the treatment and the estrogen level varies depending on the menopausal status, it is important to define the situation of each patient (Table 5) [24].

\section{Postmenopausal women}

\section{First-line setting}

- Third generation AIs Anastrozole, letrozole (nonsteroidal aromatase inhibitors, NSAI) and exemestane (steroidal aromatase inhibitor, SAI) are superior to tamoxifen. There are no differences in efficacy between the three AIs [25] (LC high; GR A).

- Fulvestrant $500 \mathrm{mg}$ has better progression free survival (PFS) than anastrozol (18 vs 13 months), without differences in OS in patients without prior exposure to ET, particularly in those with non-visceral disease [26].

- The combination of an NSAI or fulvestrant plus CDK4/6 inhibitor has consistently shown to increase PFS in about
10 months compared to ET alone, although with more toxicity, and the effect is consistent in all trials and in all clinical subgroups.

The three options (AI, fulvestrant $500 \mathrm{mg}$ and AI/fulvestrant + CDK4/6 inhibitor) are valid for the first line. Tamoxifen is also an option, if others cannot be used. The combination of ET plus CDK4/6 inhibitor is the preferred one if no other contraindications are present. [5, 22, 25, 26] (LC high; GR A).

- For patients that received chemotherapy as first line of treatment, maintenance ET is a reasonable option, although not assessed in clinical trials [5, 22]. There is somewhat less evidence for combination of ET with CDK4/6 inhibitors in this situation; so, our recommendation is to consider the use of ET alone, taking into account the toxicity and QoL variables (LC low; GR B).

\section{Second-line setting}

The second line will depend on which drug has been used as first line.

- $\mathrm{AI}$ is better than progestin, and similar to fulvestrant $250 \mathrm{mg}$. In second line fulvestrant $500 \mathrm{mg}$ is better than $250 \mathrm{mg}$ [21].

- For those patients treated with prior AIs, fulvestrant 500 would be the optimal option. [27]. Also, the alternate 
class of AI can be considered. Switching between steroidal and non-steroidal AIs produces modest additional clinical benefits, suggesting partial non-cross-resistance between the classes of inhibitor. However in these circumstances, the response rates to the second AI have generally been low [28].

- The combination of CDK4/6 inhibitors + fulvestrant has proven to be better than fulvestrant alone in patients without prior exposure to CDK4/6 inhibitors after progression to AIs, with increase in PFS [29-31] (LC high; GR A).

- Also, the combination of the mTOR (mammalian target of rapamycin) inhibitor everolimus with ET (exemestane in a phase III trial, and also with tamoxifen and fulvestrant in phase II trials) after progression to an AI leads to an increased PFS compared with ET alone, but with worse tolerance (see review in next section).

There are no data to define the best choice of treatment after progression to a CDK4/6 inhibitor in first line.

\section{Subsequent lines of therapy}

There is very limited information from prospective trials in patients with prior exposition to more than two lines of ET. In cases where a positive effect has been achieved with prior ET, those ET not previously used and progestins and other ET (Table 2) can be tested [5, 22] (LC moderate; GR B).

\section{Premenopausal women}

- There are less data for premenopausal women treated with endocrine therapy alone, as many trials with ET have included mainly postmenopausal women. However, the old data with OFS in combination with tamoxifen, small trials with OFS and AI or fulvestrant and data of premenopausal patients included in new trials of ET with CDK4/6 inhibitors have proven that the benefit in premenopausal women is comparable to that obtained in postmenopausal $[32,33]$. For all these reasons the international consensus is that the optimal management of pre/perimenopausal patients with luminal $\mathrm{ABC}$ consists of the induction of OFS or OFA in combination with another endocrine agent. Once the patient has been rendered postmenopausal, recommendations for postmenopausal apply (LC high; GR A).

- Adequate OFS for ABC premenopausal patients can be obtained through bilateral ovariectomy, continuous use of LHRH agonists or OFA through pelvic RT (this latter is not always effective, and therefore is the least preferred option) [5, 22] (LC high; GR A).

- For those patients that do not desire ovarian suppression, tamoxifen is a reasonable option ( $L C$ high; GR B).

\section{Endocrine therapy in men}

There are few data in these populations. International guidelines recommendations are that treatment should be chemical castration with GnRH analogs and then combination with ET as in postmenopausal women. Also, for those that do not want castration tamoxifen is a reasonable option [5] (LC moderate; GR A).

\section{Chemo-endocrine therapy}

There is no clear evidence that concomitant use of ET plus chemotherapy results in improvement in OS. Therefore, this combination should be discouraged outside a clinical trial [34] (LC low; GR D).

\section{Duration of ET}

ET should be continued until progressive disease or toxicity. For those patients treated with combined therapy (CDK4/6 inhibitors or everolimus) who have severe toxicity to the non-hormone component of the combination ET alone can be used until progression ( $L C h i g h ; G R A)$.

\section{Targeted therapy in advanced breast cancer}

\section{CDK4/6 inhibitors: palbociclib, ribociclib and abemaciclib}

The combination of a CDK 4/6 inhibitor with an $\mathrm{AI}$ is the preferred first-line option for most patients with endocrine-sensitive HR-positive/HER2-negative metastatic breast cancer (Table 2) [35-37] (LC high; GR A).

Recent evidence suggests the efficacy of the combination of CDK4/6 inhibitor with fulvestrant in first-line setting and endocrine-sensitive disease [30] (LC high; GR A).

The option of CDK4/6 inhibitor with an AI would also be appropriate for those patients who have not received prior treatment with a CDK4/6 inhibitor (LC moderate; $G R B)$.

For patients with endocrine-resistant HR-positive/ HER2-negative disease (Table 2) ABC, the combination of a CDK4/6 inhibitor with fulvestrant is the preferred option. [29-31, 38] (LC high; GR A). 
Table 6 Comparison of the status of authorization of CDK4/6 inhibitors

\section{EMA Indication}

PALBOCICLIB HR +/HER2 - ABC in combination with: $\mathrm{An} \mathrm{AI}^{\mathrm{a}}$

Fulvestrant, in women previously treated with $\mathrm{ET}^{\mathrm{a}}$

RIBOCICLIB Women with HR +/HER2 - ABC, in combination with an AI or Fulvestrant as initial ET or in women who have received prior $\mathrm{ET}^{\mathrm{a}}$

ABEMACICLIB Women with HR +/HER2 - ABC in combination with an AI or Fulvestrant, as initial ET or in women previously treated with $\mathrm{ET}^{\mathrm{a}}$

$H R+/ H E R 2-A B C$ hormone receptor-positive and HER2-negative Advanced Breast Cancer, $A I$ aromatase inhibitor, ET endocrine therapy

${ }^{a}$ Endocrine therapy must be combined with a luteinizing hormonereleasing hormone (LH-RH) agonist in pre or perimenopausal women

Both combinations (CDK/AI and CDK/fulvestrant) are applicable regardless of the patient's menopausal status, although pre/perimenopausal patients additionally will require ovarian function ablation or suppression.

Considering all these data, a CDK4/6 inhibitor should be added to endocrine therapy, at the latest when starting second-line endocrine therapy. Because the side effect profile of the CDK4/6 inhibitors appears substantially more tolerable than that seen with everolimus, the panel of experts recommends using CDK4/6 inhibitors rather than everolimus as the initial-targeted therapy to partner with ET.

With the exception of HR status, at present there are no validated predictive biomarkers to identify those women who could benefit from endocrine-based therapy with a CDK4/6 inhibitor (Table 6).

\section{mTOR inhibitors: everolimus}

The combination of an AI with everolimus, an mTOR inhibitor, can be a valid treatment option for patients with endocrine-resistant HR-positive/HER2-negative metastatic breast cancer, since they are likely to obtain a significantly longer median PFS compared to aromatase inhibitor monotherapy (7.8 vs 3.2 months) [39, 40].

However, as an OS benefit could not be proved [41], when considering this targeted therapy, special attention must be paid to the increased toxicity including potentially severe side effects (e.g., non-infectious pneumonitis) (LC high; $G R$ $B$ ). Primary prophylactic measures (e.g. mouthwashes with dexamethasone and meticulous oral hygiene) are recommended to prevent troublesome side effects [42]. Elderly patients should be closely monitored during treatment with proactive management of side effects.
With the exception of HR status, at present there are no validated predictive markers to identify those women who could benefit from endocrine-based therapy with a mTOR inhibitor.

\section{PARP inhibitors: olaparib and talazoparib}

The poly-(ADP-ribose)-polymerase (PARP) inhibitors olaparib and talazoparib are both useful treatment options for patients with advanced germline BRCA1/2-mutated triple-negative breast cancer (TNBC) or HER2-negative luminal-like breast cancer [43, 44]. Specifically, olaparib has been recently approved by EMA to treat metastatic breast cancer after progression on chemotherapy. Patients should have received previous treatment in the form of (neo) adjuvant therapy or up to two lines of chemotherapy with anthracyclines and taxanes for metastatic disease, and must not have platinum-resistant disease.

This recommendation is based on longer PFS (approximately 3 months), higher overall response rate, good side effect profile and an improved quality of life with both PARP inhibitors compared to physician's choice of standard chemotherapy (capecitabine, eribulin, or vinorelbine) in two randomized phase III trials (OlympiAD and EMBRACA trials) [43, 44] (LC high; GR A).

\section{Treatment of HER2-positive advanced breast cancer}

\section{First-line therapy}

The initial treatment approach to HER2-positive MBC must include a combination of chemotherapy and anti-HER2 therapy [45]. The same HER 2 targeting agent should continue beyond progression through subsequent lines of treatment [46] (LC high; GR A).

Dual-blockade with trastuzumab, pertuzumab and taxanes is the treatment of choice in the first-line setting following the results of phase III CLEOPATRA trial that demonstrates a statistical significant improvement in PFS and OS from adding pertuzumab to trastuzumab and docetaxel [47] (LC high; GR A).

Replacing taxane with vinorelbine may be considered in certain circumstances [48] (LC low; GR C).

Of note, only $10 \%$ of CLEOPATRA patients were previously exposed to trastuzumab. In the PHEREXA trial testing trastuzumab plus capecitabine with or without pertuzumab, a smaller benefit from addition of pertuzumab to trastuzumabexposed MBC patients in second-line setting was reported [49].

Trastuzumab emtansine (T-DM1) was non-inferior to trastuzumab-taxane in the phase III first-line MARIANNE study. However, there are no data regarding a head-to-head comparison between T-DM1 and dual HER2-blockade with 
trastuzumab, pertuzumab and a taxane. Consistently, T-DM1 is generally reserved for second-line setting [50]. One exception could be in cases of fast progression on/after adjuvant trastuzumab (6-12 months) or if the patient is not suitable for taxanes and dual blockade [51, 52] (LC moderate; GR B).

\section{Second-line therapy}

T-DM1 is the recommended regimen for second-line therapy, as in the phase III EMILIA trial. It demonstrated superiority over lapatinib and capecitabine in terms of PSF and OS [53] ( $L C$ high; GR A). However, it should be noted that there are limited data about T-DM1 efficacy in pertuzumab exposed patients.

Pertuzumab, trastuzumab and chemotherapy may be considered as second line in patients previously not exposed to pertuzumab, and lapatinib and capecitabine are suitable options if T-DM1 was used as first line or it is contraindicated [51, 52] (LC moderate; GR B).

\section{Third-line therapy and beyond}

Regimens currently recommended for first or second line should be considered for the later lines, if not used previously [5] (LC low; GR C).

T-DM1 demonstrated superiority over treatment of physician's choice in third and later lines in phase III TH3RESA trial [54] (LC high; GR A).

Despite the proven activity of lapatinib and capecitabine in the second line [55], this combination was inferior to T-DM1 in EMILIA trial, so it preferably should be used afterwards (LC moderate; GR B).

Trastuzumab plus different chemotherapies (vinorelbine, capecitabine, gemcitabine) may be an option if not used previously (LC low; GR C).

Trastuzumab and lapatinib are also an option [56] (LC moderate; GR B).

The number and duration of each treatment line with HER2-targeted therapy and chemotherapy combinations cannot be established. The chemotherapy should continue for approximately 6 months (or longer) and/or to the time of maximal response, depending on toxicity and in the absence of progression. When chemotherapy is stopped, clinicians should continue the HER2-targeted therapy. Available data suggest that the benefit is maintained in third line and further therapy [51, 52] (LC moderate; GR B).

\section{HR-positive HER2-positive MBC}

The first treatment approach in this population is HER2-targeted therapy plus chemotherapy ( $L C$ high; GR A).

In selected cases (including those with contraindications to chemotherapy, patient's with a strong preference against chemotherapy or those with a long disease-free interval, minimal disease burden, in particular in terms of visceral involvement, and/or strong ER/PR expression) ET plus trastuzumab or lapatinib can be an option [57, 58] (LC moderate; GR B).

If a regimen of HER2-targeting therapy and chemotherapy is started, ET may be added to the HER2-targeted therapy when chemotherapy ends [51,52] (LC low; GR C).

\section{Treatment of triple-negative advanced breast cancer}

TNBC is characterized by the absence of expression of ER, PR, and HER2. TNBC is a heterogeneous entity. There is a significant overlap of TNBC with basal-like subtype by PAM50, although they are no synonyms [59].

Chemotherapy (CT) is the standard treatment for patients with TNBC [60]. The choice of the strategy and cytotoxic agents is conditioned by a large number of factors and must be considered individually. In general, sequencing single agent chemotherapy is preferred [61], limiting combination therapies for patients with aggressive, symptomatic or life-threatening disease [51] ( $L C$ high; GR A).

The optimal duration of CT is not well established, but generally a given regimen should be used until progression of disease or unacceptable toxicity [62] (as defined together with the patient) (LC moderate; GR B).

Given the aggressiveness of the disease and the limited effective treatment options, patients with metastatic TNBC should always be offered participation in well designed, prospective, independent trials whenever such trials are available, and the patient is willing to participate ( $L C$ high; GR A).

\section{First-line treatment}

- In patients that are CT-naïve, anthracyclines or taxanes, either alone or in combinations are considered as firstline treatment [63] (LC high; GR A). This recommendation is also valid for patients with late recurrences ( $>1$ year) after completing (neo) adjuvant anthracyclines and/or taxanes.

- In patients with taxane-naïve and anthracycline-resistant MBC, or with anthracycline cumulative dose or toxicity who are being considered for further CT, taxanebased therapy, preferably as single agent would usually be considered as the therapy of choice ( $L C h i g h$; GR $A)$. In patients pretreated with adjuvant taxanes and anthracyclines, other options such as vinorelbine [64, 65] and capecitabine [66] are also available (LC moderate; $G R B)$. 
- Bevacizumab, a humanized anti-VEGF monoclonal antibody, improves PFS and overall response rate (ORR), but not OS, when combined with taxanes or capecitabine in HER2-negative MBC patients [67-70] and may be considered for selected patients with aggressive or symptomatic disease (LC moderate; $G R C$ ). In the absence of predictive biomarkers, this benefit must be weighed against its toxicity profile (hypertension, proteinuria, and hemorrhagic events) [71]. Maintenance therapy with bevacizumab plus capecitabine (compared to bevacizumab alone) after induction first-line treatment with bevacizumab plus docetaxel improves PFS and OS for HER2-negative MBC patients (PFS 11.9 vs 4.3 months) [72]. Given these results, capecitabine plus bevacizumab may be considered for selected cases after initial CT with docetaxel plus bevacizumab ( $L C$ low; GR C).

- The combination of carboplatin and gemcitabine has been accepted as control arm by EMA and FDA in randomized trials, and actually showed a significant activity (PFS of around 5 months and median OS of around 1 year as first-line therapy) [73]. The combination is active in patients resistant to anthracyclines and taxanes, and it is an acceptable option in young patients with aggressive symptomatic disease ( $L C$ moderate; GR B).

- Carboplatin as first-line treatment for patients with TNBC and/or germline BRCA1- or BRCA2-associated $\mathrm{MBC}$ (gBRCA) was as effective as docetaxel in the randomized phase III TNT trial [74]. Although there were no differences in ORR or PFS in the unselected population (ORR, carboplatin $31.4 \%$ vs docetaxel $34.0 \%$ ), gBRCA mutation carriers had an absolute difference of $34.7 \%$ in ORR $(68 \%$ vs $33 \%, p=0.03$; biomarker, treatment interaction $p=0.01$, which also translated in significant differences in PFS (6.8 vs. 3.1 months, $p=0.04$ ). Based on these results, carboplatin can be considered as an option both for unselected TNBC patients (LC moderate; GR B) and for gBRCA MBC (LC high; GR A).

- Atezolizumab in combination with nab-paclitaxel has shown to improve PFS in patients with metastatic TNBC when compared to nab-paclitaxel alone [75]. This was achieved both in the intent-to-treat population (7.2 vs 5.5 months; HR 0.80 ) and among patients with PD-L1-expressing tumors in the infiltrating immune cells. In the intention-to-treat analysis, the median OS was 21.3 months with atezolizumab plus nab-paclitaxel and 17.6 months with placebo plus nab-paclitaxel (HR $0.84 ; p=0.08$ ), and among patients with PD-L1-positive tumors, the median OS was 25.0 months and 15.5 months, respectively. Although encouraging, addi- tional results of trials testing immunotherapy agents plus chemotherapy must be awaited before a recommendation can be made to incorporate immunotherapy in first-line treatment for TNBC.

\section{Second and further lines of treatment}

There is no limit to the number of therapy lines to be proposed to metastatic TNBC patients, as long as a good quality of life is maintained [51].

In patients pretreated with an anthracycline and a taxane, and who do not need combination CT, single-agent capecitabine, vinorelbine (oral or IV), and eribulin are the preferred choices [64, 65, 76, 77] (LC moderate; GR B). Additional choices include an alternative taxane (standard or nab-paclitaxel), rechallenge with anthracyclines (liposomal formulation), gemcitabine, or platinum agents [78] ( $L C$ moderate; GR B).

\section{Chemotherapy in luminal-advanced breast cancer}

Chemotherapy should be the standard treatment for HR-positive MBC patients that are refractory to endocrine therapy, and for those women with triple-negative MBC [5] (see recommendations in the TNBC section).

Anthracyclines, taxanes, vinorelbine, capecitabine, gemcitabine and eribulin are reasonable and available options. The choice of the strategy and cytotoxic agents must be considered individually, taking into account previous therapies and their toxicities, tumor burden, time until recurrence after prior therapy, biological age, performance status, comorbidities, estimate life expectancy, need for a rapid disease/ symptom control and patient's preferences $[5,79]$. No particular chemotherapeutic agent or regimen has been able to provide consistent gains in survival in these patients [79]. In general, sequencing single-agent chemotherapy is preferred $[61,80]$, limiting combination therapies for patients with aggressive, symptomatic or life-threatening disease (at least same efficacy, less toxicity) [5] (LC high; GR A).

Evaluation of response to chemotherapy should generally occur after two to four cycles depending on the dynamics of the disease, the location and extent of metastatic involvement and type of treatment. Imaging of target lesions may be sufficient in many patients ( $L C$ moderate; GR B) [5]. Subjective and objective toxicities must be evaluated repeatedly, as well as the symptoms and performance status. Duration of each regimen and the number of regimens should be tailored to each individual patient. 


\section{First-line treatment}

- In the absence of medical contraindications or patient concerns, anthracyclines or taxanes, either alone (preferably) or in form of combinations, are considered the first-line chemotherapy of choice, particularly in patients without prior adjuvant chemotherapy or with late relapses ( $L C$ high; GR A). After pretreatment with anthracyclines, the first options are taxanes, preferably using weekly paclitaxel or docetaxel every 3 weeks ( $L C$ high; GR A). Nanoparticle albumin-bound (nab)-paclitaxel as weekly or 3-weekly schedule is an alternative option (LC moderate; GR B).

- The combination of bevacizumab plus taxanes improves PFS and ORR, but not OS versus chemotherapy alone and should also be considered a first-line chemotherapy option in selected cases [69, 70, 81] (LC moderate; GR $B$ ) (see recommendations in the TNBC section).

- In patients pretreated with adjuvant taxanes and anthracyclines, other options such as vinorelbine $[64,65]$ and capecitabine [66] are also appropriate first-line chemotherapy options ( $L C$ moderate; GR B) (see recommendations in the TNBC section).

\section{Second and further lines of chemotherapy}

- A large number of agents have shown activity as second-line chemotherapy and beyond in HR-positive MBC and may be suitable for sequential treatment in selected patients. Among them, capecitabine, vinorelbine, gemcitabine, nab-paclitaxel, liposomal doxorubicin and eribulin are approved options and can be appropriate therapies $[65,76,77,82,83]$.

- In a phase III trial in patients pretreated with taxanes and anthracyclines, eribulin was not superior to the current standard capecitabine in PFS or OS. In another phase III trial, eribulin has shown a modest improvement in OS in patients with prior taxanes, anthracyclines and capecitabine. Therefore, it is the CT drug of choice in this population (LC high; GR A).

Considering these data, capecitabine is the most recommendable first option for HR-positive MBC patients pretreated with taxanes and anthracyclines, while eribulin can be administered after progression on capecitabine ( $L C$ high; GR A).

Drug rechallenge may be appropriate in selected cases; taxane rechallenge should not be performed within 12 months after the last taxane treatment [84] (LC moderate; $G R B)$. Liposomal doxorubicin might be used in the same indications [85] (LC low; GR C).
Special situations: CNS, bone, primary tumor

\section{Treatment of central nervous system metastases}

Brain metastases is a frequent and challenging situation that affects up to $10-30 \%$ of all breast cancer patients during the course of their disease [86], being the HER2-positive and TNBC groups those with the highest incidence (up to $40 \%)$. Brain metastases are associated with the shortest survival time compared with other sites of metastatic disease in breast cancer [87], although a sizeable fraction of these patients may reach a prolonged survival ( 2 years and beyond), due to the higher efficacy of the novel local and systemic therapies.

A modified breast-graded prognostic assessment (GPA) index has recently been postulated [88, 89]. It integrates four simple clinical characteristics (age, Karnofsky score, number of brain metastases (BM) and breast cancer subtype) and may serve to guide further treatments in BM breast cancer patients.

\section{Local therapies}

Surgery Might be considered in specific circumstances: high breast-GPA index, 1-3 brain metastases, systemic disease under control, when BM are symptomatic and not responding to other therapies, and finally for diagnostic purposes [90] (LC moderate; GR B).

Stereotactic radiotherapy Stereotactic uses high conformal radiation that applies high doses of RT (15-25 Gy) in one or a few sessions [91]. This treatment is generally indicated in selected cases of oligometastatic disease $(\leq 3$ metastases) and can be considered an alternative to surgery [92] (LC moderate; GR B).

Whole brain radiation therapy (WBRT) Consists in the administration of $30 \mathrm{~Gy}$ in 10 fractions to the brain. This strategy, although palliative and indicated for symptomatic relief, has also an impact on BM breast cancer evolution as it has demonstrated a prolongation in OS versus best supportive care [93]. WBRT is generally recommended when there are multiple lesions ( $\geq 3$ metastases), and/or when lesions are higher than $3 \mathrm{~cm}$ or have a volume of $\geq 25 \mathrm{~cm}^{3}$ [94] ( $L C$ moderate; GR B).

\section{Systemic treatments}

The value of systemic treatments on local control of brain metastases is unclear. A personalized approach attending BC subtype, disposable therapies and Karnofsky score is highly advisable ( $L C$ moderate; $G R B$ ). 
Chemotherapy Although there are currently no specifically systemic treatments approved for BMBC, agents like capecitabine and topotecan, have demonstrated activity in this setting as with $\mathrm{BM}$ overall responses in the range of 38-60\% [95-98]. In the case of combinations, cisplatin and etoposide, cisplatin and temozolomide, CMF and CAF schedules reach a response rate quite similar to those obtained in extracranial disease, ranging from 38 to $76 \%$ [95].

Targeted therapies and endocrine-therapy Nowadays, targeted therapies for BMBC remain confined to HER2 advanced $\mathrm{BC}$ disease, although evidence is not clear. Improved survival with trastuzumab in HER2-positive BM breast cancer has been attributed to a better control of extracranial systemic disease [99].

Lapatinib alone does not seem particularly active in BM breast cancer, although results seem to improve when combined with capecitabine [100].

With respect to T-DM1 a subset analysis of the EMILIA trial showed that among patients with treated and stable brain metastases at baseline $(n=95)$, a significant improvement in OS was observed in the T-DM1 arm with a hazard ratio of 0.38 ( $p=0.008)$, median OS 26.8 vs 12.9 months [101]. More data from prospective trials are needed to ascertain the real efficacy of T-DM1 in BM breast cancer.

The anti-VEGF monoclonal antibody bevacizumab seems to improve results when combined with carboplatin [102, 103], but more solid evidences are needed.

Solid evidence for efficacy of endocrine therapy, PARP inhibitors, CDK4/6 inhibitors, in BM breast cancer is lacking.

\section{Role of local therapies in MBC}

They are indicated for symptoms palliation and prevention of cancer-related complications ( $L C$ moderate; GR B). Evidence regarding survival prolongation is contradictory and elusive.

- Local therapy of the primary tumor in the novo $M B C$ Routine breast surgery cannot be recommended in de novometastatic $\mathrm{BC}$ in patients who are asymptomatic at the site of their primary ( $L C$ moderate; $G R B$ ), provided that conflicting results from meta-analysis [104-106] and two prospective trials are obtained $[107,108]$.

\section{The role of surgery for extracranial metastasis in MBC}

- Can be considered after a balanced decision process and on a case-by-case basis ( $L C$ low; GR C).

- Oligometastatic disease in fit patients with long-term disease-free intervals or good response to previous sys- temic treatments could be considered as criteria for surgery with a curative intent ( $L C$ low; GR C).

\section{The role of radiotherapy for extracranial MBC}

- $\mathrm{RT}$ in MBC plays an important role in palliation (i.e., uncontrolled pain, spinal cord compression or fractures) (LC high; GR A).

\section{Treatment of bone metastases}

Bisphosphonates and other osteoclast inhibitors have shown to be effective in reducing morbidity of metastatic bone disease with respect to skeletal-related events (SREs) and should be added to anti-tumor therapy in patients with bone metastases [109] (Level of certainly high; GR A).

- The most appropriate duration of anti-resorptive therapy (bisphosphonates, denosumab) in BC patients with bone metastases is unknown. Two randomized controlled trials have demonstrated that, after at least 1 year of standard monthly antiresorptive therapy, zoledronic acid every 12 weeks is non-inferior to every 4 weeks with respect to SREs [110,111], and thus it may represent a new option in clinical practice ( $L C$ high; GR A).

\section{Compliance with ethical standards}

Conflict of interest JICH reports advisory boards and travel grants from Bristol Myers Squibb, Roche, Novartis, Celgene, Pierre Fabre, Astrazeneca, Shire, MSD, Merck and Pfizer, outside the submitted work. LCM reports advisory boards and speaking from Bristol Myers Squibb, MSD, Merck, Novartis and Roche, and Research Grants from MSD, Merck, Celgene and Roche. JG reports personal fees from Roche and Novartis during the conduct of the study. EMD reports speaker fees and advisory boards from Pfizer, Novartis, AstraZeneca, Eisai, Pierre-Fabre and Roche, personal fees from Roche, and Coordinator of electronic book of breast cancer sponsored by Novartis. MO reports personal fees from Roche/Genentech, outside the submitted work. MAS reports personal fees and non-financial support from Roche, Pfizer and Novartis, and personal fees from EISAI, outside the submitted work. IA reports personal fees from Pfizer, Novartis, Roche, Astrazeneca y Palex, non financial-support from Pfizer and Roche, and grants from Pfizer, Novartis, Roche and Astrazeneca during the conduct of the study. SA has nothing to disclose. MB reports advisory boards from Pfizer, Novartis and Lilly, honoraria from Novrtis and Pfizer and travel grants from Pfizer and Roche, outside the submitted work, SLT reports personal fees from Astra Zeneca, Novartis, Roche, Pfizer, Celgene, Pierre Fabre, Eisai; non-financial support from Novartis, Celgene, Pfizer and Pierre Fabre during the conduct of the study.

Ethical approval The current study has been performed in accordance with the ethical standards laid down in the 1964 Declaration of Helsinki and its later amendments.

Informed consent For this type of study formal consent is not required. 
OpenAccess This article is distributed under the terms of the Creative Commons Attribution 4.0 International License (http://creativeco mmons.org/licenses/by/4.0/), which permits unrestricted use, distribution, and reproduction in any medium, provided you give appropriate credit to the original author(s) and the source, provide a link to the Creative Commons license, and indicate if changes were made.

\section{References}

1. Las cifras del cáncer en España. 2018. https://www.seom.org/es/ noticias/106525-las-cifras-del-cancer-en-espana-2018 (internet; cited 2018 Aug 15).

2. Malmgren JA, Mayer M, Atwood MK, Kaplan HG. Differential presentation and survival of de novo and recurrent metastatic breast cancer over time: 1990-2010. Breast Cancer Res Treat. 2018;167:579-90.

3. (2018).Lib_El_AlamoIII_Anexo_I.pdf. https://www.geicam.org/ wp-content/uploads/2017/04/Lib_El_AlamoIII_Anexo_I.pdf (internet; cited 2018 Aug 15).

4. Grade definitions-US Preventive Services Task Force. 2018. https://www.uspreventiveservicestaskforce.org/Page/Name/grade -definitions (internet; cited 2018 Nov 7).

5. Cardoso F, Senkus E, Costa A, Papadopoulos E, Aapro M, André F, et al. 4th ESO-ESMO international consensus guidelines for advanced breast cancer (ABC 4). Ann Oncol. https://academic. oup.com/annonc/advance-article/doi/10.1093/annonc/mdy19 2/5055519 (internet; cited 2018 Aug 15).

6. Dieci MV, Barbieri E, Piacentini F, Ficarra G, Bettelli S, Dominici M, et al. Discordance in receptor status between primary and recurrent breast cancer has a prognostic impact: a single-Institution analysis. Ann Oncol. 2013;24:101-8.

7. Khatcheressian JL, Hurley P, Bantug E, Esserman LJ, Grunfeld E, Halberg F, et al. Breast cancer follow-up and management after primary treatment: American society of clinical oncology clinical practice guideline update. J Clin Oncol. 2013;31:961-5.

8. Cardoso F, Costa A, Norton L, Senkus E, Aapro M, André F, et al. ESO-ESMO 2nd international consensus guidelines for advanced breast cancer (ABC2). Breast. 2014;23:489-502.

9. Jung NY, Yoo IR, Kang BJ, Kim SH, Chae BJ, Seo YY. Clinical significance of FDG-PET/CT at the postoperative surveillance in the breast cancer patients. Breast Cancer. 2016;23:141-8.

10. Galper S, Blood E, Gelman R, Abner A, Recht A, Kohli A, et al. Prognosis after local recurrence after conservative surgery and radiation for early-stage breast cancer. Int J Radiat Oncol Biol Phys. 2005;61:348-57.

11. Poodt IGM, Vugts G, Maaskant-Braat AJG, Schipper R-J, Voogd AC, Nieuwenhuijzen GAP, et al. Risk of regional recurrence after negative repeat sentinel lymph node biopsy in patients with ipsilateral breast tumor recurrence. Ann Surg Oncol. 2018;25:1312-21.

12. Hannoun-Levi J-M, Resch A, Gal J, Kauer-Dorner D, Strnad $\mathrm{V}$, Niehoff $\mathrm{P}$, et al. Accelerated partial breast irradiation with interstitial brachytherapy as second conservative treatment for ipsilateral breast tumour recurrence: multicentric study of the GEC-ESTRO Breast Cancer Working Group. Radiother Oncol. 2013;108:226-31.

13. Pfannschmidt J, Geisbüsch P, Muley T, Hoffmann H, Dienemann H. Surgical resection of secondary chest wall tumors. Thorac Cardiovasc Surg. 2005;53:234-9.

14. Halverson KJ, Perez CA, Kuske RR, Garcia DM, Simpson JR, Fineberg B. Locoregional recurrence of breast cancer: a retrospective comparison of irradiation alone versus irradiation and systemic therapy. Am J Clin Oncol. 1992;15:93-101.
15. Laramore GE, Griffin TW, Parker RG, Gerdes AJ. The use of electron beams in treating local recurrence of breast cancer in previously irradiated fields. Cancer. 1978;41:991-5.

16. Konkin DE, Tyldesley S, Kennecke H, Speers CH, Olivotto IA, Davis N. Management and outcomes of isolated axillary node recurrence in breast cancer. Arch Surg. 2006;141:867-74.

17. Dellapasqua S, Bagnardi V, Balduzzi A, Iorfida M, Rotmensz N, Santillo B, et al. Outcomes of patients with breast cancer who present with ipsilateral supraclavicular or internal mammary lymph node metastases. Clin Breast Cancer. 2014;14:53-60.

18. Skinner HD, Strom EA, Motwani SB, Woodward WA, Green $\mathrm{MC}$, Babiera G, et al. Radiation dose escalation for loco-regional recurrence of breast cancer after mastectomy. Radiat Oncol. 2013;8:13.

19. Wapnir IL, Price KN, Anderson SJ, Robidoux A, Martín M, Nortier JWR, et al. Efficacy of chemotherapy for ER-negative and ER-positive isolated locoregional recurrence of breast cancer: final analysis of the CALOR trial. J Clin Oncol. 2018;36:1073-9.

20. Yin W, Jiang Y, Shen Z, Shao Z, Lu J. Trastuzumab in the adjuvant treatment of HER2-positive early breast cancer patients: a meta-analysis of published randomized controlled trials. PLoS One. 2011;6:e21030.

21. Gavilá J, Lopez-Tarruella S, Saura C, Muñoz M, Oliveira M, De la Cruz-Merino L, et al. SEOM clinical guidelines in metastatic breast cancer 2015. Clin Transl Oncol. 2015;17:946-55.

22. Rugo HS, Rumble RB, Macrae E, Barton DL, Connolly HK, Dickler MN, et al. Endocrine therapy for hormone receptorpositive metastatic breast cancer: American Society of Clinical Oncology Guideline. J Clin Oncol. 2016;34:3069-103.

23. Hammond MEH, Hayes DF, Dowsett M, Allred DC, Hagerty KL, Badve S, et al. American Society of Clinical Oncology/ College of American Pathologists Guideline Recommendations for immunohistochemical testing of estrogen and progesterone receptors in breast cancer. J Clin Oncol. 2010;28:2784-95.

24. NCCN Guidelines. Breast cancer (version 3.2018). https:// www.nccn.org/professionals/physician_gls/default.aspx\#breast (Internet).

25. Mauri D, Pavlidis N, Polyzos NP, Ioannidis JPA. Survival with aromatase inhibitors and inactivators versus standard hormonal therapy in advanced breast cancer: meta-analysis. J Natl Cancer Inst. 2006;98:1285-91.

26. Robertson JFR, Bondarenko IM, Trishkina E, Dvorkin M, Panasci L, Manikhas A, et al. Fulvestrant $500 \mathrm{mg}$ versus anastrozole $1 \mathrm{mg}$ for hormone receptor-positive advanced breast cancer (FALCON): an international, randomised, double-blind, phase 3 trial. Lancet. 2016;388:2997-3005.

27. Leo AD, Jerusalem G, Petruzelka L, Torres R, Bondarenko IN, Khasanov R, et al. Final overall survival: fulvestrant $500 \mathrm{mg}$ vs $250 \mathrm{mg}$ in the randomized CONFIRM Trial. J Natl Cancer Inst. 2014;106. https://academic.oup.com/jnci/article/106/1/djt33 7/2517856/Final-Overall-Survival-Fulvestrant-500mg-vs-250mg (internet; cited 2017 Jun 11).

28. Miller WR, Bartlett J, Brodie AMH, Brueggemeier RW, di Salle E, Lønning PE, et al. Aromatase inhibitors: are there differences between steroidal and nonsteroidal aromatase inhibitors and do they matter? Oncologist. 2008;13:829-37.

29. Sledge GW, Toi M, Neven P, Sohn J, Inoue K, Pivot X, et al. MONARCH 2: abemaciclib in combination with fulvestrant in women with HR +/HER2 - advanced breast cancer who had progressed while receiving endocrine therapy. J Clin Oncol. 2017;35:2875-84.

30. Slamon DJ, Neven P, Chia S, Fasching PA, De Laurentiis M, Im S-A, et al. Phase III randomized study of ribociclib and fulvestrant in hormone receptor-positive, human epidermal growth factor receptor 2-negative advanced breast cancer: MONALEESA-3. J Clin Oncol. 2018;36:2465-72. 
31. Cristofanilli M, Turner NC, Bondarenko I, Ro J, Im S-A, Masuda $\mathrm{N}$, et al. Fulvestrant plus palbociclib versus fulvestrant plus placebo for treatment of hormone-receptor-positive, HER2-negative metastatic breast cancer that progressed on previous endocrine therapy (PALOMA-3): final analysis of the multicentre, double-blind, phase 3 randomised controlled trial. Lancet Oncol. 2016;17:425-39.

32. Tancredi R, Furlanetto J, Loibl S. Endocrine therapy in premenopausal hormone receptor positive/human epidermal growth receptor 2 negative metastatic breast cancer: between guidelines and literature. Oncologist. 2018;23(8):974-81.

33. Tripathy D, Im S-A, Colleoni M, Franke F, Bardia A, Harbeck $\mathrm{N}$, et al. Ribociclib plus endocrine therapy for premenopausal women with hormone-receptor-positive, advanced breast cancer (MONALEESA-7): a randomised phase 3 trial. Lancet Oncol. 2018;19:904-15.

34. Stockler M, Wilcken NRC, Ghersi D, Simes RJ. Systematic reviews of chemotherapy and endocrine therapy in metastatic breast cancer. Cancer Treat Rev. 2000;26:151-68.

35. Finn RS, Martin M, Rugo HS, Jones S, Im S-A, Gelmon K, et al. Palbociclib and letrozole in advanced breast cancer. N Engl J Med. 2016;375:1925-36.

36. Hortobagyi GN, Stemmer SM, Burris HA, Yap Y-S, Sonke GS, Paluch-Shimon S, et al. Ribociclib as first-line therapy for HR-positive, advanced breast cancer. N Engl J Med. 2016;375:1738-48.

37. Hortobagyi GN, Stemmer SM, Burris HA, Yap YS, Sonke GS, Paluch-Shimon S, et al. Updated results from MONALEESA-2, a phase III trial of first-line ribociclib plus letrozole versus placebo plus letrozole in hormone receptor-positive, HER2-negative advanced breast cancer. Ann Oncol. 2018;29:1541-7.

38. Harbeck N, Iyer S, Turner N, Cristofanilli M, Ro J, André F, et al. Quality of life with palbociclib plus fulvestrant in previously treated hormone receptor-positive, HER2-negative metastatic breast cancer: patient-reported outcomes from the PALOMA-3 trial. Ann Oncol. 2016;27:1047-54.

39. Baselga J, Campone M, Piccart M, Burris HA, Rugo HS, Sahmoud T, et al. Everolimus in postmenopausal hormonereceptor-positive advanced breast cancer. N Engl J Med. 2012;366:520-9.

40. Yardley DA, Noguchi S, Pritchard KI, Burris HA, Baselga J, Gnant M, et al. Everolimus plus exemestane in postmenopausal patients with $\mathrm{HR}+$ breast cancer: BOLERO-2 final progressionfree survival analysis. Adv Ther. 2013;30:870-84.

41. Piccart M, Hortobagyi GN, Campone M, Pritchard KI, Lebrun F, Ito Y, et al. Everolimus plus exemestane for hormonereceptor-positive, human epidermal growth factor receptor2-negative advanced breast cancer: overall survival results from BOLERO-2. Ann Oncol. 2014;25:2357-62.

42. Rugo HS, Seneviratne L, Beck JT, Glaspy JA, Peguero JA, Pluard TJ, et al. Prevention of everolimus-related stomatitis in women with hormone receptor-positive, HER2-negative metastatic breast cancer using dexamethasone mouthwash (SWISH): a single-arm, phase 2 trial. Lancet Oncol. 2017;18:654-62.

43. Robson M, Im S-A, Senkus E, Xu B, Domchek SM, Masuda $\mathrm{N}$, et al. Olaparib for metastatic breast cancer in patients with a germline BRCA mutation. N Engl J Med. 2017;377:523-33.

44. Litton JK, Rugo HS, Ettl J, Hurvitz SA, Gonçalves A, Lee K-H, et al. Talazoparib in patients with advanced breast cancer and a germline BRCA mutation. N Engl J Med. 2018;379(8):753-63.

45. Slamon DJ, Leyland-Jones B, Shak S, Fuchs H, Paton V, Bajamonde A, et al. Use of chemotherapy plus a monoclonal antibody against HER2 for metastatic breast cancer that overexpresses HER2. N Engl J Med. 2001;344:783-92.
46. von Minckwitz G, du Bois A, Schmidt M, Maass N, Cufer T, de Jongh FE, et al. Trastuzumab beyond progression in human epidermal growth factor receptor 2-positive advanced breast cancer: a german breast group 26/breast international group 03-05 study. J Clin Oncol. 2009;27:1999-2006.

47. Swain SM, Baselga J, Kim S-B, Ro J, Semiglazov V, Campone $\mathrm{M}$, et al. Pertuzumab, trastuzumab, and docetaxel in HER2-positive metastatic breast cancer. N Engl J Med. 2015;372:724-34.

48. Perez EA, López-Vega JM, Petit T, Zamagni C, Easton V, Kamber J, et al. Safety and efficacy of vinorelbine in combination with pertuzumab and trastuzumab for first-line treatment of patients with HER2-positive locally advanced or metastatic breast cancer: VELVET Cohort 1 final results. Breast Cancer Res. 2016;18:126.

49. Urruticoechea A, Rizwanullah M, Im S-A, Ruiz ACS, Láng I, Tomasello G, et al. Randomized phase III trial of trastuzumab plus capecitabine with or without pertuzumab in patients with human epidermal growth factor receptor 2-positive metastatic breast cancer who experienced disease progression during or after trastuzumab-based therapy. J Clin Oncol. 2017;35:3030-8.

50. Perez EA, Barrios C, Eiermann W, Toi M, Im Y-H, Conte P, et al. Trastuzumab emtansine with or without pertuzumab versus trastuzumab plus taxane for human epidermal growth factor receptor 2-positive, advanced breast cancer: primary results from the phase III MARIANNE study. J Clin Oncol. 2016;35:141-8.

51. Cardoso F, Costa A, Senkus E, Aapro M, André F, Barrios CH, et al. 3rd ESO-ESMO international consensus guidelines for advanced breast cancer (ABC 3). Ann Oncol. 2017;28:16-33.

52. Giordano SH, Temin S, Chandarlapaty S, Crews JR, Esteva FJ, Kirshner JJ, et al. Systemic therapy for patients with advanced human epidermal growth factor receptor 2-positive breast cancer: ASCO clinical practice guideline update. J Clin Oncol. 2018;36(26):2736-40.

53. Diéras V, Miles D, Verma S, Pegram M, Welslau M, Baselga J, et al. Trastuzumab emtansine versus capecitabine plus lapatinib in patients with previously treated HER2-positive advanced breast cancer (EMILIA): a descriptive analysis of final overall survival results from a randomised, open-label, phase 3 trial. Lancet Oncol. 2017;18:732-42.

54. Krop IE, Kim S-B, Martin AG, LoRusso PM, Ferrero J-M, Badovinac-Crnjevic T, et al. Trastuzumab emtansine versus treatment of physician's choice in patients with previously treated HER2-positive metastatic breast cancer (TH3RESA): final overall survival results from a randomised open-label phase 3 trial. Lancet Oncoly. 2017;18:743-54.

55. Cameron D, Casey M, Oliva C, Newstat B, Imwalle B, Geyer CE. Lapatinib plus capecitabine in women with HER-2-positive advanced breast cancer: final survival analysis of a phase III randomized trial. Oncologist. 2010;15:924-34.

56. Blackwell KL, Burstein HJ, Storniolo AM, Rugo HS, Sledge G, Aktan G, et al. Overall survival benefit with lapatinib in combination with trastuzumab for patients with human epidermal growth factor receptor 2-positive metastatic breast cancer: final results from the EGF104900 study. J Clin Oncol. 2012;30:2585-92.

57. Kaufman B, Mackey JR, Clemens MR, Bapsy PP, Vaid A, Wardley A, et al. Trastuzumab plus anastrozole versus anastrozole alone for the treatment of postmenopausal women with human epidermal growth factor receptor 2-positive, hormone receptorpositive metastatic breast cancer: results from the randomized phase III TAnDEM study. J Clin Oncol. 2009;27:5529-37.

58. Johnston S, Pippen J, Pivot X, Lichinitser M, Sadeghi S, Dieras $\mathrm{V}$, et al. Lapatinib combined with letrozole versus letrozole and placebo as first-line therapy for postmenopausal hormone receptor-positive metastatic breast cancer. J Clin Oncol. 2009;27:5538-46. 
59. Lehmann BD, Pietenpol JA. Clinical implications of molecular heterogeneity in triple negative breast cancer. Breast. 2015;24:S36-40.

60. Mayer IA, Abramson VG, Lehmann BD, Pietenpol JA. New strategies for triple-negative breast cancer-deciphering the heterogeneity. Clin Cancer Res. 2014;20:782-90.

61. Dear RF, McGeechan K, Jenkins MC, Barratt A, Tattersall MHN, Wilcken N. Combination versus sequential single agent chemotherapy for metastatic breast cancer. Cochrane Database Syst Rev. 2013. https://doi.org/10.1002/14651858.CD008792.pub2

62. Gennari A, Stockler M, Puntoni M, Sormani M, Nanni O, Amadori D, et al. Duration of chemotherapy for metastatic breast cancer: a systematic review and meta-analysis of randomized clinical trials. J Clin Oncol. 2011;29:2144-9.

63. Piccart-Gebhart MJ, Burzykowski T, Buyse M, Sledge G, Carmichael J, Lück H-J, et al. Taxanes alone or in combination with anthracyclines as first-line therapy of patients with metastatic breast cancer. J Clin Oncol. 2008;26:1980-6.

64. Xu Y-C, Wang H-X, Tang L, Ma Y, Zhang F-C. A systematic review of vinorelbine for the treatment of breast cancer. Breast J. 2013;19:180-8.

65. Aapro M, Finek J. Oral vinorelbine in metastatic breast cancer: a review of current clinical trial results. Cancer Treatt Rev. 2012;38:120-6.

66. Chan A, Verrill M. Capecitabine and vinorelbine in metastatic breast cancer. Eur J Cancer. 2009;45:2253-65.

67. Miles DW, Diéras V, Cortés J, Duenne A-A, Yi J, O'Shaughnessy $J$. First-line bevacizumab in combination with chemotherapy for HER2-negative metastatic breast cancer: pooled and subgroup analyses of data from 2447 patients. Ann Oncol. 2013;24:2773-80.

68. Miles DW, Chan A, Dirix LY, Cortés J, Pivot X, Tomczak P, et al. Phase III study of bevacizumab plus docetaxel compared with placebo plus docetaxel for the first-line treatment of human epidermal growth factor receptor 2-negative metastatic breast cancer. J Clin Oncol. 2010;28:3239-47.

69. Miller K, Wang M, Gralow J, Dickler M, Cobleigh M, Perez EA, et al. Paclitaxel plus bevacizumab versus paclitaxel alone for metastatic breast cancer. N Engl J Med. 2007;357:2666-76.

70. Robert NJ, Diéras V, Glaspy J, Brufsky AM, Bondarenko I, Lipatov ON, et al. RIBBON-1: randomized, double-blind, placebo-controlled, phase III trial of chemotherapy with or without bevacizumab for first-line treatment of human epidermal growth factor receptor 2-negative, locally recurrent or metastatic breast cancer. J Clin Oncol. 2011;29:1252-60.

71. Oostendorp LJ, Stalmeier PF, Donders ART, van der Graaf WT, Ottevanger PB. Efficacy and safety of palliative chemotherapy for patients with advanced breast cancer pretreated with anthracyclines and taxanes: a systematic review. Lancet Oncol. 2011;12:1053-61.

72. Gligorov J, Doval D, Bines J, Alba E, Cortes P, Pierga J-Y, et al. Maintenance capecitabine and bevacizumab versus bevacizumab alone after initial first-line bevacizumab and docetaxel for patients with HER2-negative metastatic breast cancer (IMELDA): a randomised, open-label, phase 3 trial. Lancet Oncol. 2014;15:1351-60.

73. O'Shaughnessy J, Schwartzberg L, Danso MA, Miller KD, Rugo HS, Neubauer M, et al. Phase III study of Iniparib plus gemcitabine and carboplatin versus gemcitabine and carboplatin in patients with metastatic triple-negative breast cancer. J Clin Oncol. 2014;32:3840-7.

74. Tutt A, Tovey H, Cheang MCU, Kernaghan S, Kilburn L, Gazinska P, et al. Carboplatin in BRCA1/2-mutated and triple-negative breast cancer BRCAness subgroups: the TNT trial. Nat Med. 2018;24:628-37.
75. Schmid P, Adams S, Rugo HS, Schneeweiss A, Barrios CH, Iwata $\mathrm{H}$, et al. Atezolizumab and Nab-paclitaxel in advanced triplenegative breast cancer. N Engl J Med. 2018;379(22):2108-21.

76. Cortes J, O'Shaughnessy J, Loesch D, Blum JL, Vahdat LT, Petrakova K, et al. Eribulin monotherapy versus treatment of physician's choice in patients with metastatic breast cancer (EMBRACE): a phase 3 open-label randomised study. Lancet. 2011;377:914-23.

77. Kaufman PA, Awada A, Twelves C, Yelle L, Perez EA, Velikova $\mathrm{G}$, et al. Phase III open-label randomized study of eribulin mesylate versus capecitabine in patients with locally advanced or metastatic breast cancer previously treated with an anthracycline and a taxane. J Clin Oncol. 2015;33:594-601.

78. Montero AJ, Adams B, Diaz-Montero CM, Glück S. Nab-paclitaxel in the treatment of metastatic breast cancer: a comprehensive review. Expert Rev Clin Pharmacol. 2011;4:329-34.

79. González A, Lluch A, Aba E, Albanell J, Antón A, Álvarez I, et al. A definition for aggressive disease in patients with HER-2 negative metastatic breast cancer: an expert consensus of the Spanish Society of Medical Oncology (SEOM). Clin Transl Oncol. 2017;19:616-24.

80. Qi W-X, Tang L, He A, Shen Z, Yao Y. Comparison between doublet agents versus single agent in metastatic breast cancer patients previously treated with an anthracycline and a taxane: a meta-analysis of four phase III trials. Breast. 2013;22:314-9.

81. Miles DW, Chan A, Dirix LY, Cortés J, Pivot X, Tomczak P, et al. Phase III study of bevacizumab plus docetaxel compared with placebo plus docetaxel for the first-line treatment of human epidermal growth factor receptor 2-negative metastatic breast cancer. J Clin Oncol. 2010;28:3239-47.

82. Batist G, Ramakrishnan G, Rao CS, Chandrasekharan A, Gutheil J, Guthrie T, et al. Reduced cardiotoxicity and preserved antitumor efficacy of liposome-encapsulated doxorubicin and cyclophosphamide compared with conventional doxorubicin and cyclophosphamide in a randomized, multicenter trial of metastatic breast cancer. J Clin Oncol. 2001;19:1444-54.

83. Rom J, Bechstein S, Domschke C, Golatta M, Mayer C, Heil J, et al. Efficacy and toxicity profile of pegylated liposomal doxorubicin (Caelyx) in patients with advanced breast cancer. Anticancer Drugs. 2014;25:219-24.

84. Guo X, Loibl S, Untch M, Möbus V, Schwedler K, Fasching PA, et al. Re-challenging taxanes in recurrent breast cancer in patients treated with (neo-)adjuvant taxane-based therapy. Breast Care (Basel). 2011;6:279-83.

85. Twelves C, Jove M, Gombos A, Awada A. Cytotoxic chemotherapy: still the mainstay of clinical practice for all subtypes metastatic breast cancer. Crit Rev Oncol Hematol. 2016;100:74-87.

86. Lin NU, Bellon JR, Winer EP. CNS metastases in breast cancer. JCO. 2004;22:3608-17.

87. Kennecke H, Yerushalmi R, Woods R, Cheang MCU, Voduc D, Speers $\mathrm{CH}$, et al. Metastatic behavior of breast cancer subtypes. J Clin Oncol. 2010;28:3271-7.

88. Subbiah IM, Lei X, Weinberg JS, Sulman EP, Chavez-MacGregor M, Tripathy D, et al. Validation and development of a modified breast graded prognostic assessment as a tool for survival in patients with breast cancer and brain metastases. J Clin Oncol. 2015;33:2239-45.

89. Sperduto PW, Kased N, Roberge D, Xu Z, Shanley R, Luo X, et al. Summary report on the graded prognostic assessment: an accurate and facile diagnosis-specific tool to estimate survival for patients with brain metastases. J Clin Oncol. 2012;30:419-25.

90. Patchell RA, Tibbs PA, Walsh JW, Dempsey RJ, Maruyama $\mathrm{Y}$, Kryscio RJ, et al. A randomized trial of surgery in the treatment of single metastases to the brain. N Engl J Med. 1990;322:494-500. 
91. Hasegawa T, Kondziolka D, Flickinger JC, Germanwala A, Lunsford LD. Brain metastases treated with radiosurgery alone: an alternative to whole brain radiotherapy? Neurosurgery. 2003;52:1318-26 (discussion 1326).

92. Gil-Gil MJ, Martinez-Garcia M, Sierra A, Conesa G, del Barco S, González-Jimenez S, et al. Breast cancer brain metastases: a review of the literature and a current multidisciplinary management guideline. Clin Transl Oncol. 2014;16:436-46.

93. Hofer S, Pestalozzi BC. Treatment of breast cancer brain metastases. Eur J Pharmacol. 2013;717:84-7.

94. Kaal EC, Niël CG, Vecht CJ. Therapeutic management of brain metastasis. Lancet Neurol. 2005;4:289-98.

95. Arslan C, Dizdar O, Altundag K. Chemotherapy and biological treatment options in breast cancer patients with brain metastasis: an update. Expert Opin Pharmacother. 2014;15:1643-58.

96. Ekenel M, Hormigo AM, Peak S, DeAngelis LM, Abrey LE. Capecitabine therapy of central nervous system metastases from breast cancer. J Neurooncol. 2007;85:223-7.

97. Naskhletashvili DR, Gorbounova VA, Bychkov MB, Chmutin GE, Karakhan VB, Krat VB. Capecitabine monotherapy for patients with brain metastases from advanced breast cancer. $\mathbf{J}$ Clin Oncol. 2009;27:1102.

98. Oberhoff C, Kieback DG, Würstlein R, Deertz H, Sehouli J, van Soest $\mathrm{C}$, et al. Topotecan chemotherapy in patients with breast cancer and brain metastases: results of a pilot study. ORT. 2001;24:256-60.

99. Ramakrishna N, Temin S, Chandarlapaty S, Crews JR, Davidson NE, Esteva FJ, et al. Recommendations on disease management for patients with advanced human epidermal growth factor receptor 2-positive breast cancer and brain metastases: American Society of clinical oncology clinical practice guideline. J Clin Oncol. 2014;32:2100-8.

100. Bachelot T, Romieu G, Campone M, Diéras V, Cropet C, Dalenc $\mathrm{F}$, et al. Lapatinib plus capecitabine in patients with previously untreated brain metastases from HER2-positive metastatic breast cancer (LANDSCAPE): a single-group phase 2 study. Lancet Oncol. 2013;14:64-71.

101. Krop IE, Lin NU, Blackwell K, Guardino E, Huober J, Lu M, et al. Trastuzumab emtansine (T-DM1) versus lapatinib plus capecitabine in patients with HER2-positive metastatic breast cancer and central nervous system metastases: a retrospective, exploratory analysis in EMILIA. Ann Oncol. 2015;26:113-9.

102. Lin NU, Gelman RS, Younger WJ, Sohl J, Freedman RA, Sorensen AG, et al. Phase II trial of carboplatin (C) and bevacizumab (BEV) in patients (pts) with breast cancer brain metastases (BCBM). J Clin Oncol. 2013;31:513.

103. Lu Y-S, Chen W-W, Lin C-H, Tseng L-M, Yeh D-C, Wu P-F, et al. Bevacizumab, etoposide, and cisplatin (BEEP) in brain metastases of breast cancer progressing from radiotherapy: Results of the first stage of a multicenter phase II study. J Clin Oncol. 2012;30:1079.

104. Petrelli F, Barni S. Surgery of primary tumors in stage IV breast cancer: an updated meta-analysis of published studies with metaregression. Med Oncol. 2012;29:3282-90.

105. Ruiterkamp J, Voogd AC, Bosscha K, Tjan-Heijnen VCG, Ernst MF. Impact of breast surgery on survival in patients with distant metastases at initial presentation: a systematic review of the literature. Breast Cancer Res Treat. 2010;120:9-16.

106. Harris E, Barry M, Kell MR. Meta-analysis to determine if surgical resection of the primary tumour in the setting of stage IV breast cancer impacts on survival. Ann Surg Oncol. 2013;20:2828-34.

107. Soran A, Ozmen V, Ozbas S, Karanlik H, Muslumanoglu M, Igci A, et al. Randomized trial comparing resection of primary tumor with no surgery in stage IV breast cancer at presentation: protocol MF07-01. Ann Surg Oncol. 2018. https://doi.org/10.1245/ s10434-018-6494-6 (internet; cited 2018 Aug 24).

108. Badwe R, Hawaldar R, Nair N, Kaushik R, Parmar V, Siddique S, et al. Locoregional treatment versus no treatment of the primary tumour in metastatic breast cancer: an open-label randomised controlled trial. Lancet Oncol. 2015;16:1380-8.

109. Aapro M, Abrahamsson PA, Body JJ, Coleman RE, Colomer R, Costa L, et al. Guidance on the use of bisphosphonates in solid tumours: recommendations of an international expert panel. Ann Oncol. 2008;19:420-32.

110. Amadori D, Aglietta M, Alessi B, Gianni L, Ibrahim T, Farina $\mathrm{G}$, et al. Efficacy and safety of 12-weekly versus 4-weekly zoledronic acid for prolonged treatment of patients with bone metastases from breast cancer (ZOOM): a phase 3, open-label, randomised, non-inferiority trial. Lancet Oncol. 2013;14:663-70.

111. Hortobagyi GN, Poznak CV, Harker WG, Gradishar WJ, Chew $\mathrm{H}$, Dakhil SR, et al. Continued treatment effect of zoledronic acid dosing every 12 vs 4 weeks in women with breast cancer metastatic to bone: the OPTIMIZE-2 randomized clinical trial. JAMA Oncol. 2017;3:906-12. 